\title{
Effects of Stress Stimulation on Protein Folding/Degradation Pathway Related Proteins in Different Levels of Exhaustive Exercise
}

YING JIN ${ }^{1 *}$ AND Q. H. XIA ${ }^{1}$

Teaching Department of Physical and Military Education, Jingdezhen Ceramic University, Jingdezhen 333000, China, ${ }^{1}$ College of Pharmacy, Wonkwang University, Iksan 54538, Korea

Jin et al.: Effects of Stress Stimulation on Protein Folding/Degradation Pathway

\begin{abstract}
The pathways related to cell protein folding and degradation need to be elucidated because of training was set. The results showed that chaperonin containing tailless complex polypeptide the large number of proteins involved, the complex relationship between proteins and the lack of research on the effects of movement and cell protein folding and degradation. In order to analyze the effect of stress stimulation on protein folding/degradation pathway related proteins under different levels of exhaustive exercise, C57 Black 6 male mice of $4 \mathrm{w}$ old were selected from the experimental animal center of the Academy of Military Medical Sciences and different intensity of treadmill exercise 1 beta, protein subunit alpha type-1 and protein subunit beta type-7 protein in insulin resistance mice bone increased significantly and insulin resistance improved significantly after $6 \mathrm{w}$ of aerobic treadmill exercise. High intensity endurance exercise increased the expression of collagen volume fraction and type I collagen in right atrium and right ventricle $(p<0.01)$ and the longer exercise time, the greater the increased range, and had no significant effect on the expression of collagen volume fraction and type I collagen in left ventricle. Although moderate intensity exercise promoted the expression of collagen volume fraction and collagen $I$ in myocardium, there was no statistical significance.
\end{abstract}

Key words: Varying degrees, exhaustive exercise, stress stimulation, protein folding/degradation, related proteins

With the improvement of people's living standards and the improvement of social medical and health conditions, metabolic diseases have become the main diseases that seriously affect human health. It is very urgent to study the pathogenesis of metabolic diseases and take effective treatment measures to delay the progress of metabolic diseases. Lack of exercise may lead to over nutrition, over saturation of energy, imbalance and disorder of metabolism and metabolic diseases. Long term regular aerobic exercise can promote the metabolism of substances and improve the internal environment by increasing the energy consumption of the body. It has significant effect on health promotion and prevention of metabolic diseases. In recent years, research on exercise genomics has confirmed that exercise can play an important role in improving the health level of the body and preventing chronic metabolic diseases such as obesity and Insulin
Resistance (IR) by affecting the expression of skeletal muscle related genes ${ }^{[1]}$. In organisms, the flow of biological information can be divided into two parts. One is the transmission of one-dimensional information, which will be stored in the Deoxyribonucleic acid(DNA) sequence and transferred into the primary sequence of protein through transcription and translation; the other is the peptide chain which formed the natural structure of protein through the folding process to obtain biological activity and express life information ${ }^{[2]}$. As the expression vector of life information, the specific spatial structure formed by protein folding is the basis of its biological function. Chaperonin Containing Tailless Complex Polypeptide 1 (CCT-1) is one of the important elements of protein folding pathway in cells and proteasome is an important component of Adenosine Triphosphate (ATP) dependent protein degradation pathway in cells. They are involved in the 
formation of protein folding/degradation signalling pathway, maintaining the normal spatial structure and normal biological function of protein ${ }^{[3]}$. The decrease of protein folding/degradation related protein expression can induce the increase of Amyloid-Beta peptide (A $\beta)$ expression $^{[4]}$. The latest research shows that $A \beta$ can not only accumulate in brain tissue and interfere with insulin signal conduction in neurons, but also appear in skeletal muscle tissue of diabetic animal model, causing oxidative stress reaction in skeletal muscle tissue, secondary IR and a variety of skeletal muscle lesions. Type 2 Diabetes Mellitus (T2DM) is the most common type of diabetes at present and IR is an important pathophysiological feature of T2DM ${ }^{[3]}$. It has been shown that the abnormal cell protein folding and degradation caused by abnormal cell protein folding/ degradation signal pathway is closely related to the occurrence of IR. Our previous proteomic studies reported that aerobic exercise can improve IR related lipid metabolism disorder, inhibit oxidative stress response of skeletal muscle tissue and increase insulin sensitivity of skeletal muscle tissue ${ }^{[5]}$. Exercise-induced arrhythmia is a problem of great concern in sports medicine and sports science due to the large amount of exercise. Long term high intensity exercise results in the excessive increase of collagen. A certain proportion of endurance athletes have myocardial fibrosis, which may be an important pathological change that causes exercise induced myocardial injury and arrhythmia. Therefore, this paper focuses on the effects of stress stimulation on protein folding/degradation pathway related proteins and cardiac proteins under different levels of exhaustive exercise ${ }^{[6]}$.

\section{MATERIALS AND METHODS}

\section{Establishment of animal model:}

$80 \mathrm{C} 57$ Black 6 (C57BL/6) male mice of $4 \mathrm{w}$ old provided by the experimental animal center of the Military Medical Sciences Academy were selected with an average weight of $(14.82 \pm 0.41) \mathrm{g}$. After $1 \mathrm{w}$ of adaptive feeding, the mice were randomly divided into two groups: Normal diet group (20 mice) and IR model group (60 mice), which were fed with basic and high fat diet respectively. The components of high fat feed were protein $20 \% \mathrm{kcal}$, carbohydrate $35 \% \mathrm{kcal}$ and fat $45 \% \mathrm{kcal}$. After $10 \mathrm{w}$, Oral Glucose Tolerance Test (OGTT) and fin were used to determine whether the IR model was established successfully. After identification, the success rate of IR modelling was $66.7 \%$, a total of 40 mice were successfully modelled. They were randomly divided into high fat diet exercise group (HE, n=20) and high fat diet quiet group (HC, $\mathrm{n}=20$ ). The two groups continued to take high fat diet, while HE group took $6 \mathrm{w}$ of aerobic treadmill exercise at the same time. Before exercise, mice need to carry out adaptive training to adapt to the animal running platform (Huaibei Zhenghua biological instrument equipment Co., Ltd., computer controlled six way small animal running platform). For the first time, the running platform slope is set as 0 , the speed is $10 \mathrm{~m} / \mathrm{min}$ and the speed increases until $12 \mathrm{~m} / \mathrm{min}$ on the next day (the intensity is equivalent to $75 \%$ Maximal Oxygen Uptake $\left(\mathrm{VO}_{2} \max \right)$ ). After 1 $\mathrm{w}$ of adaptive training, the running platform training is continuously carried out for $6 \mathrm{w}, 5 \mathrm{~d} / \mathrm{w}, 1$ time/d and 60 $\mathrm{min} /$ time.

High intensity exercise training can lead to heart injury or arrhythmia. Its mechanism is related to long term high intensity exercise leading to myocardial energy metabolism disorder, myocarditis reaction, ion channel abnormality and cytoskeleton protein damage and other factors. However, its etiology, pathology and pathogenesis are not clear about the impact on protein folding/degradation pathway related proteins $^{[7]}$. According to the clinical pathological study, myocardial fibrosis is a kind of histopathological change of the heart after long term abnormal stimulation. The structural change is often manifested in the proliferation of fibroblasts and the increase of collagen based extracellular matrix, the maladjustment of extracellular matrix synthesis and degradation, the increase of Collagen Proportion of Type I (Col-I), Collagen Proportion of Type III (Col-III) and the ratio of collagen types ${ }^{[8]}$. The functional changes of myocardial fibrosis are increased stiffness, decreased compliance, decreased contractility and decreased cardiac function. Myocardial fibrosis is an important material basis for the occurrence of arrhythmia. Arrhythmia is induced by the formation of re-entry loop, conduction delay and conduction block ${ }^{[9]}$.

In order to analyze the effect of stress stimulation on myocardial collagen of protein folding/degradation pathway under different levels of exhaustive exercise, 72 out of 80 mice were randomly selected for $7 \mathrm{~d}$ adaptive treadmill training. The training plan is to train $15 \mathrm{~min}$ every day, the speed of running platform is $15 \mathrm{~m} / \mathrm{min}$ and the gradient of running platform is $0^{\circ}$. After the adaptive training, the mice that could not adapt to the treadmill training were removed. The remaining mice were randomly divided into three groups: quiet control group $(\mathrm{C})$, moderate intensity exercise group (M) and high intensity exercise group $(\mathrm{H})$. The speed of running platform in group $M$ was $15.2 \mathrm{~m} / \mathrm{min}$ with a slope of $5^{\circ}$; the speed of running platform in group $\mathrm{H}$ was $25 \mathrm{~m} /$ min with a slope of $10^{\circ}$. Group $\mathrm{H}$ ran at $15 \mathrm{~m} / \mathrm{min}$ for 5 
min, then gradually increased to $28 \mathrm{~m} / \mathrm{min}$ in $5 \mathrm{~min}$ and maintained until the end of training. After 8,12 and $16 \mathrm{w}$ of exercise, the samples were taken ${ }^{[10]}$.

\section{Animal tissue sample retention:}

After the training, the animals are fasted for $16 \mathrm{~h}$. The quadriceps femoris of mice were isolated immediately after the animals were anesthetized by intraperitoneal injection of chloral hydrate. The quadriceps femoris were frozen rapidly in liquid nitrogen and then stored in a refrigerator at $-80^{\circ}$ for extraction of whole protein. Among them, the Collagen Volume Fraction (CVF) of cardiac collagen was extracted by Sirius red staining ${ }^{[11]}$. Collagen I protein was detected by immunofluorescence and the fluorescence intensity was expressed by Integral Gray Scale (IOS) ${ }^{[12]}$.

\section{Protein extraction and two-Dimensional electrophoresis:}

(2D)

Take out the skeletal muscle tissue from liquid nitrogen, put it into a mortar and grind it into powder shape with liquid nitrogen, weigh it accurately and then add the tissue lysate (40 mM Tris(hydroxymethyl)aminomethane hydrochloride (Tris $\mathrm{HCl}$ ), $7 \mathrm{M}$ urea, $2 \mathrm{M}$ Thiourea, $4 \%$ 3-[(3-cholamidopropyl)dimethylammonio]-1propanesulfonate (CHAPS), 1 \% Dithiothreitol (DTT), 1 mM Ethylenediamine Tetraacetic Acid (EDTA)) into 1.5 $\mathrm{ml}$ Eppendorf tube according to the mass to volume ratio of 1:10, at the same time, add cocktail protease inhibitor according to the proportion of 50:1 and break the tissue to complete cleavage by ultrasound ${ }^{[13]}$. After $20 \mathrm{~min}$ of ice bath, the supernatant was centrifuged at $4^{\circ}$ and 14000 $\mathrm{r} / \mathrm{min}$ for $20 \mathrm{~min}$. The supernatant was protein extract. The samples were quantitated by Bradford method, then packed separately and stored at $-80^{\circ}$ for future use.

Inorganic Pigments (IPG) was used to prefabricate the dry adhesive strips ( $\mathrm{pH} 3-10)$, the sample amount of each strip was $100 \mu \mathrm{g}$ and the first phase solid phase $\mathrm{pH}$ gradient isoelectric focusing was carried out according to the instructions of Bio-Rad Company and the total voltage time product was $80000 \mathrm{Vh}$. The adhesive strips were then balanced two times in the Sodium Dodecyl Sulfate (SDS) equilibrium solution (1.5 M Tris $\mathrm{HCl}, \mathrm{pH} 8.8,50$ mM 30 \% Glycerol, 6 M Urea, 2 \% SDS, Bromophenol blue trace). The strips were taken out for the vertical phase of the second phase and separated by a polyacrylamide gel with a concentration of $13 \%{ }^{[14]}$. Constant current $40 \mathrm{~mA}$ for $40 \mathrm{~min}, 60 \mathrm{~mA}$ for $5 \mathrm{~h}$ until the front edge of bromophenol blue reaches the bottom of the glass plate.

\section{Silver nitrate and Coomassie brilliant blue staining:}

Silver staining: After electrophoresis, take out the gel and cut the corner to mark ${ }^{[15]}$. Put it into the plastic tray for silver nitrate dyeing. Sodium Dodecyl Sulphate-Polyacrylamide Gel Electrophoresis (SDS-PAGE) adhesive was fixed with $50 \mathrm{ml}$ glacial acetic acid and $200 \mathrm{ml}$ anhydrous ethanol to $500 \mathrm{ml}$ for $30 \mathrm{~min}$, then sensitized with $1 \mathrm{~g}$ of sodium thiosulfate, $150 \mathrm{ml}$ of anhydrous ethanol and 34 $\mathrm{g}$ of sodium acetate for $30 \mathrm{~min}$, washed with water for 3 times, 5 min each time, then treated with $1.25 \mathrm{~g}$ of silver nitrate and $200 \mu \mathrm{l}$ of formaldehyde for $20 \mathrm{~min}$, washed twice and developed with $12.5 \mathrm{~g}$ and $100 \mu \mathrm{l}$ of anhydrous sodium carbonate for $1 \mathrm{~min}$ each time until the background appeared, EDTA stopped developing.

Examination and dyeing: R-350 was used in $0.1 \%$ Coomassie brilliant blue dye solution at $100^{\circ}$ for $10 \mathrm{~min}$ and then decolourization by $10 \%$ acetic acid ${ }^{[8]}$.

\section{Image acquisition and analysis:}

The silver staining Two-Dimensional Gel Electrophoresis (2-DE) image was acquired by gel imaging system ImageScaner ${ }^{[16]}$. The 2-DE atlas was analyzed by imagemaster 2D platinum V5.0 analysis software (purchased from Amersham pharmacy biotech company in Sweden) for image cutting, correction, background subtraction, point detection, standardization and matching, and the difference point was defined as the one that increased or decreased 1.5 times.

\section{Enzyme digestion and Mass Spectrometry (MS):}

The candidate protein spots on 2-DE were removed for decolourization of protein spots and intraglue trypsin digestion. $1 \mu \mathrm{l}$ of the sample after enzyme digestion was mixed with equal volume of matrix Alpha-Cyano-4hydroxycinnamic acid (HCCA) and then the spots were dried naturally at room temperature and put into ultra-flex instrument (purchased from Bruker company) for MatrixAssisted Laser Desorption/Ionization-Time of Flight-Mass Spectrometry (MALDI-TOF-MS) identification. The quality of Peptide Mass Fingerprinting (PMF) was 3501400 Da. Use mascot (www.matrixscience.com, matrix science Ltd, UK) retrieval software to retrieve (National Center for Biotechnology Information (NCBI) NonRedundant (NR) database by PMF. The search parameters of mascot software database (www.matrixscience.com) are set as follows: Trypsin is selected as protease and the variable modification of protein is carbomidomethyl and methionine oxidation. The mass error of MS is $0.3 \mathrm{Da}$ and the maximum allowable omission site is 1 . 
The candidate protein spots on silver stained 2-DE were decolorized and trypsin digested in the gel. After that, the Synapt high definition MS (purchased from waters company) was used for Liquid Chromatography with Tandem Mass Spectrometry (LC-MS-MS) analysis. The quality collection range was MS: 350-1400 Da, MS/ MS: 50-2000 Da. After being processed by PLGS v2.3, NCBI NR was retrieved by MS ion of mascot retrieval software ${ }^{[17]}$. Search conditions: The protease is trypsin and the variable modification of protein is carbomidomethyl and oxidation of methionine. The mass error of MS and MS/MS is $0.2 \mathrm{Da}$ and the maximum allowable leakage site is 1 .

\section{Statistical analysis:}

Use ImageMaster 2D Platinum V5.0 analysis software to test whether there is statistical significance in the difference of relative protein content ${ }^{[18]}$.

\section{RESULTS AND DISCUSSION}

Compared with $\mathrm{HC}$ group, HE histone expression profile changed significantly. The main features are the change of gray value and the increase and decrease of protein spots in 2D electrophoresis. Image Master 2D Platinum V5.0 software was used to automatically detect the protein spots in the 2-DE map. The protein density of the gel was 1.5 times higher than that of the protein and 43 spots were detected. According to the matching and comparative analysis of protein spots, 22 protein spots with different expression (increased or decreased) were found after the elimination of high abundance proteins such as keratin. Among them, 5 protein spots were closely related to IR of exercise improvement and their expression difference multiples were as follows: protein spot 1 (ChaperoninContaining TCP-1 beta (CCT-1 $\beta)$ ) and protein spot 2 (Ester Hydrolase Chromosome 11 Open Reading Frame 54 (C11orf54) Homolog) were new proteins after exercise ${ }^{[19]}$. After exercise, protein spot 3 (Fibrinogen Beta Chain Precursor) decreased by $38 \%$, protein spot 4 (Proteasome Subunit Beta Type-7 Precursor) increased by 3.27 times and protein spot 5 (Proteasome Subunit Alpha Type-1) increased by 1.67 times as shown in fig. 1 .

Protein spots were identified by MS. The difference in expression points were matched and analyzed by ImageMaster 2D Platinum V5.0 software and NCBI NR database was searched by mascot software to obtain the identification results of protein spots (Table 1). Table 2 showed the detailed results of ester hydrolase C11orf54 homolog identified by LC-MS/MS.

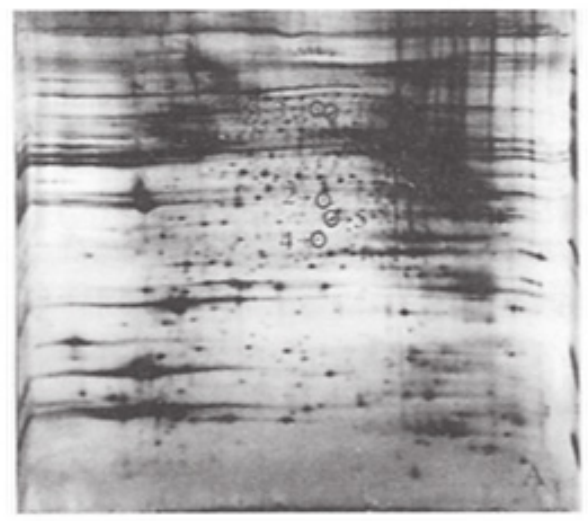

(a) Group HC

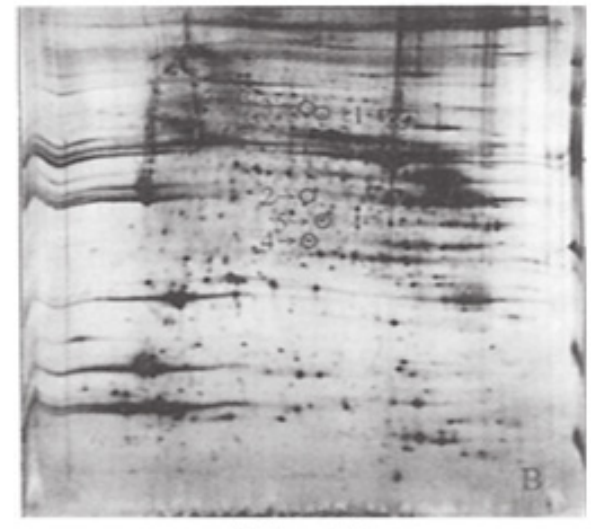

(b) Group HE

Fig. 1: Schematic diagram of differential expression protein 
TABLE 1: IDENTIFICATION RESULTS OF DIFFERENTIAL EXPRESSION OF PROTEINS BY MS

\begin{tabular}{|c|c|c|c|c|c|c|c|c|}
\hline $\begin{array}{l}\text { Serial } \\
\text { number }\end{array}$ & $\begin{array}{l}\text { Accession } \\
\text { number GI }\end{array}$ & $\begin{array}{l}\text { Protein } \\
\text { name }\end{array}$ & $\begin{array}{l}\text { Matching } \\
\text { score }\end{array}$ & $\begin{array}{l}\text { Matching } \\
\text { peptide } \\
\text { segment }\end{array}$ & $\begin{array}{l}\text { Coverage } \\
\text { rate }\end{array}$ & $\begin{array}{l}\text { Theory } \\
\text { Molecular } \\
\text { Weight } \\
(\mathrm{MW})\end{array}$ & $\begin{array}{c}\text { Theory } \\
\text { Isoelectric } \\
\text { Point (PI) }\end{array}$ & $\begin{array}{c}\text { Difference } \\
\text { multiple }\end{array}$ \\
\hline 1 & 468547 & $\begin{array}{l}\text { CTT-1 } \beta \\
\text { subunit }\end{array}$ & 378 & 9 & $22.10 \%$ & 57412 & 2.98 & + \\
\hline 2 & 19526927 & $\begin{array}{c}\text { Ester } \\
\text { hydrolase } \\
\text { C11orf54 } \\
\text { homolog }\end{array}$ & 44 & 3 & $8.10 \%$ & 34974 & 5.857 & + \\
\hline 3 & 33859808 & $\begin{array}{l}\text { Fibrinogen } \\
\text { beta chain } \\
\text { precursor }\end{array}$ & 233 & 23 & $45.10 \%$ & 54719 & 6.69 & 0.383466 \\
\hline 4 & 6755207 & $\begin{array}{l}\text { Proteasome } \\
\text { subunit } \\
\text { beta Type-7 } \\
\text { precursor }\end{array}$ & 77 & 2 & $5.10 \%$ & 29873 & 8.15 & 3.2724 \\
\hline 5 & 33563283 & $\begin{array}{l}\text { Proteasome } \\
\text { subunit } \\
\text { alpha Type-1 }\end{array}$ & 89 & 9 & $36.10 \%$ & 29529 & 6.01 & 1.66825 \\
\hline
\end{tabular}

Note: $(+)$ indicates the results showed that the skeletal muscle protein of the group was higher than that of HC group

TABLE 2: FRAGMENT ION SPECTRA OF C11ORF54 HOMOLOGUES OF ESTER HYDROLASE (GI, 19523926), MASCOT SCORE $=43$

\begin{tabular}{lcccccc}
\hline $\begin{array}{l}\text { Mass charge } \\
\text { ratio }\end{array}$ & Experiment Mr1 & Actual Mr2 & $\begin{array}{c}\text { Difference } \\
\text { value }\end{array}$ & Score & Expected value & Peptide segment \\
\hline 657.3051 & 1312.5955 & 1312.5905 & 0.0052 & 40 & 0.063 & $\begin{array}{r}\text { R. TGELNFVSCMR. Q+ } \\
\text { Carbamidomethyl (C) }\end{array}$ \\
841.4955 & 1680.9763 & 1680.9815 & -0.0053 & 5 & $1.60 E+03$ & R. IAEVGGVPLLPLVNK.K \\
\hline
\end{tabular}

The results showed that CCT- $\beta$, protein subunit alphatype-1 and protein subunit beta type-7 precursor protein content in the skeletal muscle of IR mice increased significantly and IR improved significantly after $6 \mathrm{w}$ of aerobic treadmill exercise. The increase of proteasome content can enhance the degradation of $\mathrm{A} \beta$ and the amino acids produced after protein degradation may be used to resynthesize proteins and polypeptides, while the increase of CCT- $\beta$ protein content can help in the formation of newly synthesized proteins and maintain the correct spatial structure, reduce the production of $A \beta$ and also assist in the degradation of proteasome ${ }^{[20]}$. It is concluded that the two proteins may improve IR by accelerating amino acid turnover, promoting protein remodeling after exercise, reducing $\mathrm{A} \beta$ protein content, inhibiting oxidative stress response and activation of related signaling pathways.

Fibrinogen precursor is the precursor protein of fibrinogen synthesized by hepatocytes and megakaryocytes. Some studies have shown that fibrinogen in blood is closely related to inflammatory response, its content changes can reflect the systemic inflammatory status and can also be used as an indicator to predict the occurrence and development of diabetes, but the role of fibrinogen in skeletal muscle is rarely reported. The results showed that the content of fibrinogen precursor in skeletal muscle decreased significantly and IR symptoms improved significantly after exercise. It is concluded that fibrinogen in skeletal muscle may be involved in the inflammatory response induced by $\mathrm{A} \beta$ protein as an inflammatory signal molecule.

The changes of collagen content in mice are shown in Table 3, fig. 2 and fig. 3. After $8 \mathrm{w}$ of exercise, compared with group $\mathrm{C}, \mathrm{CVF}$ in right atrium, right ventricle and left ventricle of mice in group $\mathrm{M}$ and group $\mathrm{H}$ increased, but there was no significant difference. Among them, CVF in group $\mathrm{H}$ increased significantly. 
TABLE 3: CHANGES OF CVF IN MYOCARDIUM OF MICE IN THIS STUDY

\begin{tabular}{lcccc}
\hline Time coding & & C & M & H \\
\hline $8 \mathrm{w}$ & Right atrium & $2.208 \pm 0.323$ & $2.129 \pm 0.385$ & $2.568 \pm 0.595$ \\
& Right ventricle & $1.914 \pm 0.482$ & $2.134 \pm 0.358$ & $2.413 \pm 0.184$ \\
& Left ventricle & $1.681 \pm 0.626$ & $1.788 \pm 0.377$ & $1.829 \pm 0.458$ \\
$12 \mathrm{w}$ & Right atrium & $2.061 \pm 0.238$ & $2.214 \pm 0.254$ & $3.176 \pm 0.428^{* *} \# \#$ \\
& Right ventricle & $2.266 \pm 0.449$ & $2.559 \pm 0.543$ & $3.221 \pm 0.861$ \\
$16 \mathrm{w}$ & Left ventricle & $0.242 \pm 0.267$ & $1.815 \pm 0.275$ & $2.368 \pm 0.433$ \\
& Right atrium & $1.985 \pm 0.309$ & $2.348 \pm 0.137$ & $4.296 \pm 0.417^{* *} \# \#$ \\
& Right ventricle & $2.428 \pm 0.434$ & $2.873 \pm 0.362$ & $4.393 \pm 0.543^{* *} \# \#$ \\
& Left ventricle & $2.372 \pm 0.588$ & $2.295 \pm 0.533$ & $2.602 \pm 0.407$ \\
\hline
\end{tabular}

Note: ${ }^{* *} \mathrm{p}<0.01$, compared with group $C ;{ }^{*} p<0.01$, compared with group $M ; n=8$
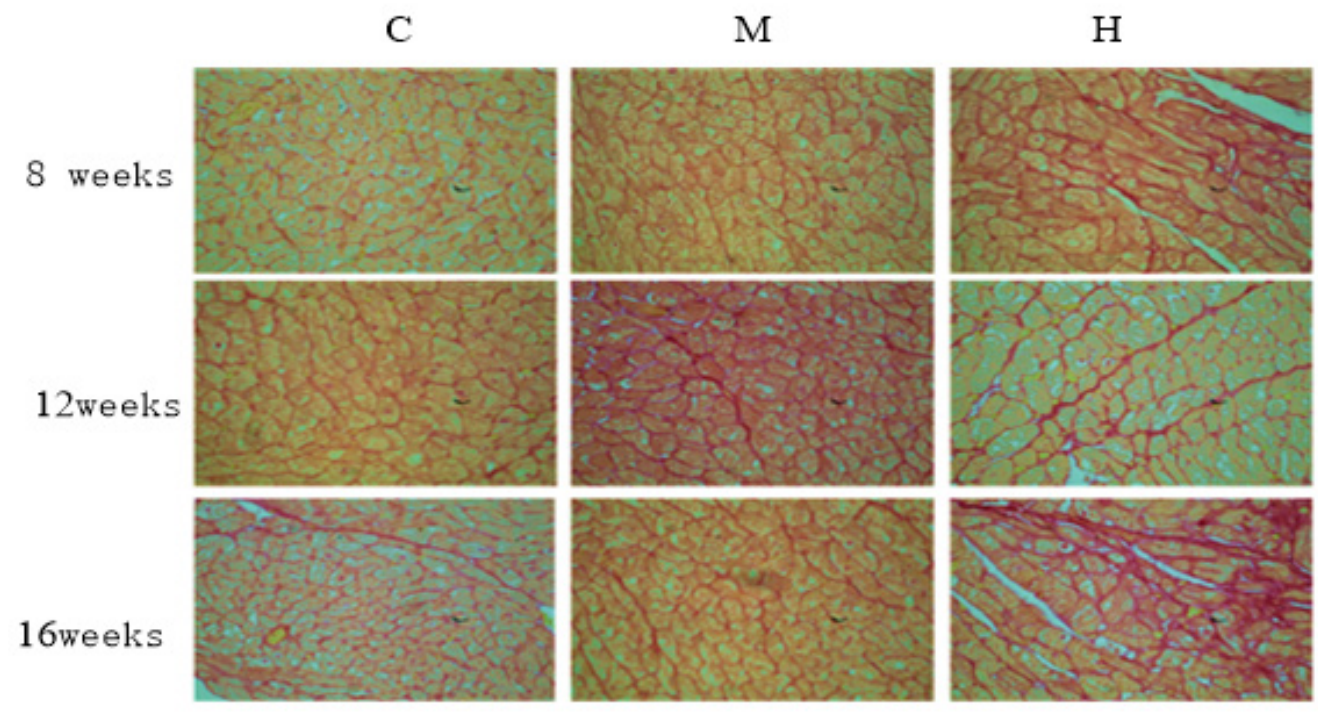

Fig. 2: Sirius red staining of right ventricular myocardium in rats

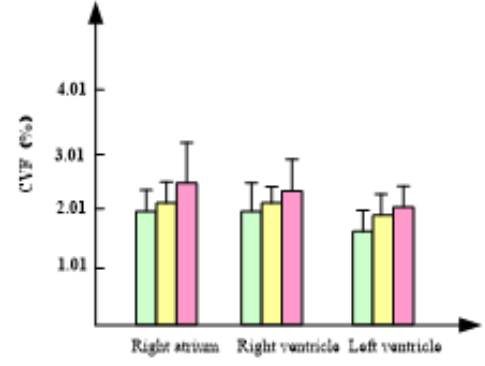

(a) 8 weeks

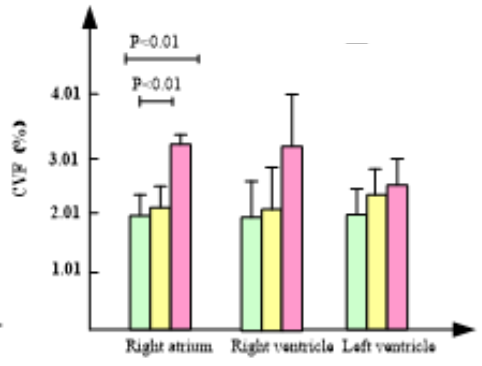

(b) 12 weeks

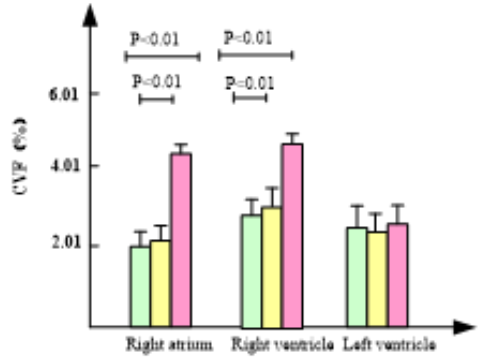

(c) 16 weeks

Fig. 3: Schematic diagram of CVF in myocardium of rats in this study, ( $\square$ ) C; ( $\square$ ) M; ( $($ ) H 
After $12 \mathrm{w}$ of exercise, CVF of right atrium and right ventricle in group $\mathrm{M}$ was lower than that in group $\mathrm{C}$, while CVF of left ventricle was higher than that in group $\mathrm{C}$, but there was no significant difference ${ }^{[21]}$. CVF of right atrium in group $\mathrm{H}$ was significantly higher than that in group $\mathrm{C}$ and group $\mathrm{M}(\mathrm{p}<0.01)$ by 0.54 and 0.43 times, respectively. Compared with group $\mathrm{C}, \mathrm{CVF}$ of right and left ventricles in group $\mathrm{H}$ also increased, but there was no significant difference.

After $16 \mathrm{w}$ of exercise, CVF of right atrium and right ventricle in group $\mathrm{M}$ was lower than that in group $\mathrm{C}$, while CVF of left ventricle was higher than that in group $\mathrm{C}$, but there was no significant difference. $\mathrm{CVF}$ of right atrium in group $\mathrm{H}$ was significantly higher than that in group $C$ and group $M(p<0.01)$ and increased by 1.16 and 0.83 times respectively. $\mathrm{CVF}$ of right ventricle in group $\mathrm{H}$ was significantly higher than that in group $\mathrm{C}$ and group $\mathrm{M}$ ( $<<0.01$ ), increased by 1.78 and 1.53 times respectively.

In conclusion, compared with group $\mathrm{C}$, group $\mathrm{M}$ had no significant change in $\mathrm{CVF}$, while group $\mathrm{H}$ significantly promoted the increase of CVF in right atrium and right ventricle.

The results of immunofluorescence staining are shown in fig. 4 and fig. 5. Compared with group C, 8 w moderate exercise had no significant effect on the expression of Col-I in right atrium, right ventricle and left ventricle. The expression of Col-I in right atrium of group $\mathrm{H}$ was significantly higher than that of group $C(p<0.05)$ and the expression of Col-I in right and left ventricles was also higher than that of group $\mathrm{C}$, but there was no statistical significance.

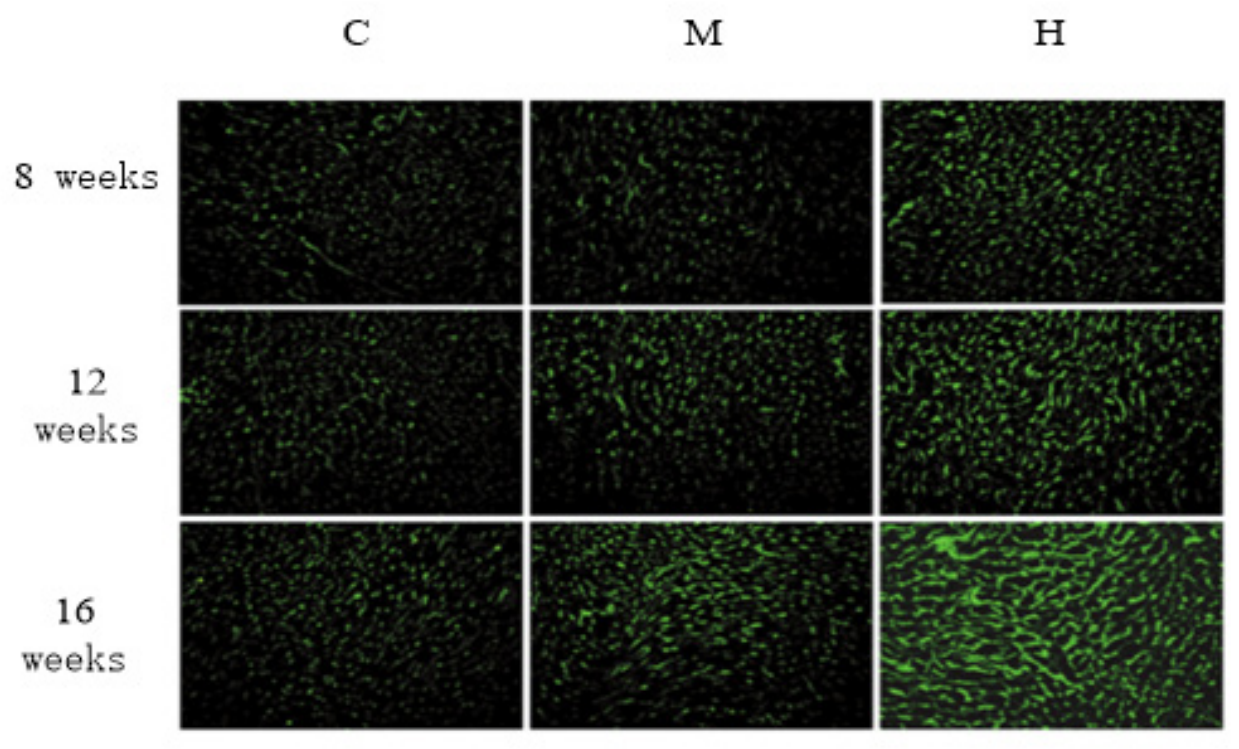

Fig. 4: Immunofluorescence staining results

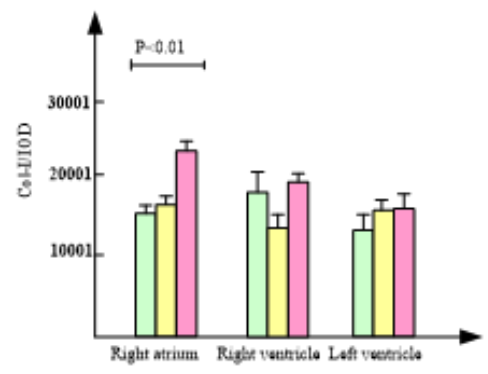

(a) 8 weeks

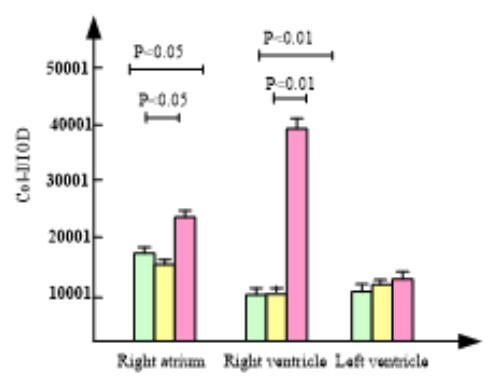

(b) 12 weeks

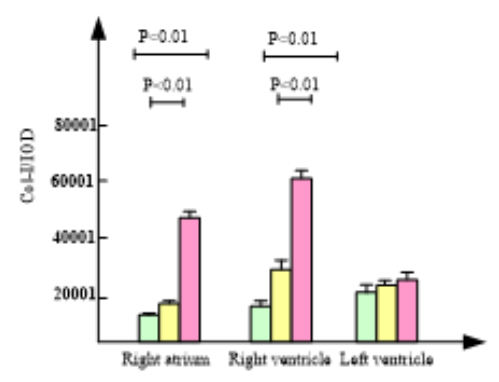

(c) 16 weels

Fig. 5: Schematic diagram of integral optical density of Col-I in this study, ( $\square$ ) C; ( $\square$ ) M; ( $\square$ ) H 
At $12 \mathrm{w}$, isointensity exercise had no significant effect on the expression of Col-I in right atrium, right ventricle and left ventricle. At $12 \mathrm{w}$, the expression of Col-I in right atrium of group $\mathrm{H}$ was significantly higher than that of group $\mathrm{C}$ and group $\mathrm{M}(\mathrm{p}<0.01)$.

At $16 \mathrm{w}$, the expression of Col-I in right atrium, right ventricle and left ventricle was higher than that in group $\mathrm{C}$, but there was no significant difference. At $16 \mathrm{w}$, the expression of Col-I in right atrium and right ventricle of $\mathrm{H}$ group was significantly higher than that of group $\mathrm{C}$ and group $\mathrm{M}(\mathrm{p}<0.01)$.

In conclusion, compared with group $\mathrm{C}$, moderate intensity exercise had no significant effect on the expression of Col-I in myocardium, while group $\mathrm{H}$ significantly promoted the expression of Col-I in right atrium and right ventricle, but had no significant effect on the expression of Col-I in left ventricle.

IR refers to the decrease of insulin-mediated glucose uptake and utilization by tissue cells, which is the common pathophysiological basis of obesity, T2DM and other metabolic diseases. However, the effect of aerobic exercise on the prevention and treatment of obesity, IR, T2DM and other metabolic diseases has been recognized, but the molecular mechanism of aerobic exercise in improving metabolism is not fully clear. In order to explore the molecular mechanism of improving IR by aerobic exercise, we established IR model by feeding C57BL/6 mice with high fat diet for $10 \mathrm{w}$ and then intervened IR mice with aerobic exercise for $6 \mathrm{w}$. After $6 \mathrm{w}$ of aerobic exercise, the fin level and OGTT curve of IR mice tended to normal level and IR symptoms improved significantly. It was found that the expression of proteins related to protein folding/degradation pathway in skeletal muscle cells changed significantly after exercise by proteomics, suggesting that it may play an important role in improving IR during exercise. It was found that CCT- $\beta$, proteasome subunit beta type-7 precursor, proteasome subunit alpha type-1, ester hydrolase C11orf54 homolog and fibrinogen beta chain precursor were related to cell protein folding/ degradation pathway.

CCT- $\beta$ is one of the eight subunits of CCT. As a chaperone protein of cytoplasm, CCT- $\beta$ is an important member of molecular chaperone family. Molecular chaperone is a kind of protein that can assist other peptides to fold, assemble and degrade in cells and it is an important element of protein folding pathway in cells. CCT, as the first line of defence against protein misfolding and accumulation, can combine with intracellular protein, maintain its spatial conformation, prevent protein aggregation and also assist in the degradation of a variety of abnormal protein folding diseases and avoid the production of toxic products. Proteasome subunit beta type-7 and proteasome subunit alpha type-1 transformed by proteasome subunit beta type-7 precursor are involved in the formation of cellular proteasome $20 \mathrm{~S}$ core granules. The $26 \mathrm{~S}$ proteasome composed of $20 \mathrm{~S}$ core granules and 19S regulatory granules is the most common form of proteasome. Proteasome is a giant protein complex in the nucleus and cytoplasm of eukaryotes. Ubiquitin-Proteasome Pathway (UPP) composed of ubiquitin and ubiquitin is an important protein degradation pathway in cells. UPP is involved in the regulation of cell protein folding, cell inflammatory response and cell signal transduction and it is also the second line of defence against protein structural abnormalities. The change of its pathway protein will directly lead to the accumulation of hamartogen and the secondary cell dysfunction.

Proteasome and CCT- $\beta$ are involved in the regulation of protein folding and degradation, and are important elements of protein folding/degradation signaling pathway. The cell folding/degradation signaling pathway composed of the two can maintain the normal spatial structure of the protein, prevent the accumulation of the protein and maintain the biological function of the protein. Both proteasome dysfunction and CCT expression decrease can cause abnormal protein folding/degradation pathway and induce the production of $A \beta$ protein. $A \beta$ is a peptide protein composed of 39-43 amino acid residues, which has the characteristics of aggregation into amyloid fibres. It can induce the production of Reactive Oxygen Species (ROS) through many ways, causing extensive damage of brain neurons and secondary Alzheimer's Disease (AD). The latest research shows that $A \beta$ accumulates in the skeletal muscle of T2DM animal model and participates in the formation of IR. Hyperglycemia can aggravate the burden of oxidative stress in skeletal muscle, significantly increase the expression of $\mathrm{A} \beta$ protein, increase its aggregation in skeletal muscle, which will aggravate the oxidative stress response in skeletal muscle and then enhance the expression of $A \beta$ protein, forming a vicious cycle. At the same time, as a proteasome inhibitor, $A \beta$ protein can competitively inhibit the chymotrypsin like activity of its $20 \mathrm{~S}$ core particles and hinder its normal function. UPP is the main degradation pathway of $A \beta$ and its inhibition can also increase the accumulation of $A \beta$ protein. $A \beta$ can lead to oxidative stress in skeletal muscle, which can reduce the sensitivity of skeletal muscle to insulin, activate inflammatory signaling pathway in skeletal muscle and interfere with insulin signaling. 
Studies have shown that ester hydrolase C11orf54 homolog is a protein expressed by the homologous gene of Open Reading Frame 54 (ORF54) in mice and human chromosome 11. At present, there are few reports on its specific functions. Proteomic studies have shown that it may be involved in the regulation of protein folding/ degradation. The results showed that after $6 \mathrm{w}$ of aerobic exercise, the expression of ester hydrolase C11 orf54 homolog protein increased, suggesting that ester hydrolase C11orf54 homolog, proteasome and CCT- $\beta$ may participate in the regulation of protein folding/degradation signaling pathway in IR mice skeletal muscle.

The results of Sirius red staining showed that, compared with group $\mathrm{C}$, moderate intensity exercise at 8,12 and $16 \mathrm{w}$ increased collagen in right atrium, right ventricle and $\mathrm{CVF}$ in left ventricle, but there was no significant difference. After $12 \mathrm{w}$ of intensive exercise, CVF of right ventricle was significantly higher than that of group $\mathrm{C}$ and group $\mathrm{M}$ and CVF of right ventricle and left ventricle was also higher than that of group $\mathrm{C}$, but there was no statistical significance. After $16 \mathrm{w}$ of high intensity endurance exercise, CVF of right atrium and right ventricle were significantly higher than that of group $\mathrm{C}$ and group $\mathrm{M}$, while CVF of left ventricle had no significant change. Results in group $\mathrm{M}$, exercise did not cause myocardial fibrosis. After $12 \mathrm{w}$ of high-intensity endurance exercise, the right atrium of mice developed fibrosis. With the extension of exercise time, the degree of atrial fibrosis increased and the fibrosis of the right ventricle appeared in the $16^{\text {th }} \mathrm{w}$.

Col-I accounts for more than $85 \%$ of the total collagen in myocardium and it is the main component of myocardial interstitium. It was found that the expression of Col-I in different parts of myocardium was different and timedependent with the change of collagen content. The results showed that $12 \mathrm{w}$ and $16 \mathrm{w}$ of intensive exercise resulted in a significant increase of Col-I in the right atrium and right ventricle, and the larger the increase was with time, while moderate exercise had no significant effect on the myocardial Col-I.

In this paper, proteomics technology was used to study the effect of aerobic exercise on the expression of protein in the skeletal muscle of IR mice for $6 \mathrm{w}$ and to analyze the differential expression of protein in group HE and group $\mathrm{HC}$, among which the protein folding/degradation pathway related proteins CCT-1 $\beta$ subunit, proteasome subunit beta type-7 precursor and proteasome subunit alpha type-1 were significantly increased after exercise, suggesting that $6 \mathrm{w}$ aerobic exercise may improve the IR induced by high-fat diet by increasing the expression of protein folding/degradation pathway related proteins in the skeletal muscle of IR mice; long-term high-intensity endurance exercise results in a significant increase of collagen content in the right atrium and right ventricle of mice and a significant increase of CVF, especially Col-I. After $12 \mathrm{w}$ of high-intensity endurance exercise, the right atrium of mice developed fibrosis and the degree of atrial fibrosis increased with time, while the fibrosis of the right ventricle appeared in the $16^{\text {th }} \mathrm{W}$. Excessive increase of collagen fibre will affect cardiac contractility and electrocardiographic conduction, forming the pathological basis of exercise-induced arrhythmia.

\section{Conflict of interests:}

The authors declared no conflicts of interest.

\section{REFERENCES}

1. Chaffey PK, Guan X, Wang X, Ruan Y, Li Y, Miller SG, et al. Quantitative effects of O-linked glycans on protein folding. Biochemistry 2017;56(34):4539-48.

2. Lv Y. Research on noise subspace culling based on threeelement array sonar. J Chin Acad Electron Inf Technol 2017;12(4):406-9.

3. Jiang SH, Li J, Dong FY, Yang JY, Liu DJ, Yang XM, et al. Increased serotonin signaling contributes to the Warburg effect in pancreatic tumor cells under metabolic stress and promotes growth of pancreatic tumors in mice. Gastroenterology 2017;153(1):277-91.

4. Cheng M, Kong L, Zhang B. Space-vector PWM control of novel modularized fluxswitching permanent magnet linear machine with complementary magnetic circuits based on ATMEGA128; 2018.

5. Sun L. Repetitive-control-based control technology for microgrid inverters. J Power Supply 2018;16:38-44.

6. Wen J, Scoles DR, Facelli JC. Effects of the enlargement of polyglutamine segments on the structure and folding of ataxin-2 and ataxin-3 proteins. J Biomol Struct Dyn 2017;35(3):504-19.

7. $\mathrm{Hu}$ Y. Main problems and solutions of mechanical and electrical equipment installation in intelligent building branch project. Autom Instrum 2017;4:159-61.

8. Moreno-Gonzalez I, Edwards III G, Salvadores N, Shahnawaz M, Diaz-Espinoza R, Soto C. Molecular interaction between type 2 diabetes and Alzheimer's disease through cross-seeding of protein misfolding. Mol Psychiatry 2017;22(9):1327-34.

9. Li X. An anti-occlusion tracking algorithm for moving objects. J Jilin Univ 2017;55:1207-12.

10. Cash DD, Feigon J. Structure and folding of the Tetrahymena telomerase RNA pseudoknot. Nucleic Acids Res 2017;45(1):482-95.

11. Qiao L. Under the 3D Image visual movement key feature extraction method of improvement. Comput Simul 2017;34:216-9.

12. Dhouafli Z, Cuanalo-Contreras K, Hayouni EA, Mays CE, Soto $\mathrm{C}$, Ines Moreno-Gonzalez. Inhibition of protein misfolding and aggregation by natural phenolic compounds. Cell Mol Life Sci 2018;75(19):3521-38.

13. Suárez E, Adelman JL, Zuckerman DM. Mechanism beyond markov models: History information is needed for unbiased pathway reconstruction of protein folding. Biophys $\mathrm{J}$ 2017;112(3):289a-90a. 
14. Malhotra P, Jethva PN, Udgaonkar J. Chemical denaturants smoothen ruggedness on the free energy landscape of protein folding. Biochemistry 2017;56(31):4053-63.

15. Carlson TM, Lam KW, Lam CW, He JZ, Maynard JH, Cavagnero S. Naked-eye detection of reversible protein folding and unfolding in aqueous solution. J Chem Educ 2017;94(3):350-5.

16. Pilipczuk J, Zalewska-Piątek B, Bruździak P, Czub J, Wieczór $\mathrm{M}$, Olszewski M, et al. Role of the disulfide bond in stabilizing and folding of the fimbrial protein DraE from uropathogenic Escherichia coli. J Biol Chem 2017;292(39):16136-49.

17. Iyer BR, Zadafiya P, Vetal PV, Mahalakshmi R. Energetics of side-chain partitioning of $\beta$-signal residues in unassisted folding of a transmembrane $\beta$-barrel protein. J Biol Chem 2017;292(29):12351-65.

18. Okada S, Matsusaki M, Arai K, Hidaka Y, Inaba K, Okumura $\mathrm{M}$, et al. Coupling effects of thiol and urea-type groups for promotion of oxidative protein folding. Chem Commun 2019;55(6):759-62.
19. Ge S, Liu Z, Furuta Y, Peng W. Adsorption characteristics of sulfur solution by acticarbon against drinking-water toxicosis. Saudi J Biol Sci 2017;24(6):1355-60.

20. Guo T, Lin Q, Li X, Nie Y, Wang L, Shi L, et al. Octacosanol attenuates inflammation in both RAW264.7 macrophages and a mouse model of colitis. J Agric Food Chem 2017;65(18):364758.

21. Nie Y, Luo F, Lina Q. Dietary nutrition and gut microflora: A promising target for treating diseases. Trends Food Sci Technol 2018;75:72-80.

This is an open access article distributed under the terms of the Creative Commons Attribution-NonCommercial-ShareAlike 3.0 License, which allows others to remix, tweak, and build upon the work non-commercially, as long as the author is credited and the new creations are licensed under the identical terms

This article was originally published in a special issue, "Diagnostic and Therapeutic Advances in Biomedical Research and Pharmaceutical Sciences"

Indian J Pharm Sci 2021:83(5)Spl Issue “249-258” 